Morphological Differences and Their Effects

\title{
on the Mechanical Properties of Titanium Oxides Thin Film Obtained via Anodization Process
}

\author{
N. SARICA ${ }^{a, *}, Z$ Z.Z. ÖZTÜRK ${ }^{b}$, C. BINDAL ${ }^{a}$ AND A.H. ÜÇIŞIK ${ }^{c}$ \\ ${ }^{a}$ Sakarya University, Department of Metallurgical and Materials Engineering, Adapazarı, Turkey \\ ${ }^{b}$ Gebze Technical University, Department of Physics, Kocaeli, Turkey \\ ${ }^{c}$ Atılım University, Board of Trustees, Ankara, Turkey
}

\begin{abstract}
It is well known that anodization process is helpful for obtaining metallic oxides on the metal surfaces. The advantages of this process are used in this study to obtain rough surfaces consisting of titanium oxides and solid solutions of titanium and oxygen. Two different voltages were applied to a pure titanium foil during two process time periods. In all process conditions, titanium oxide thin films were successfully obtained on the base material. Depending on the duration of the process and the voltages applied, the amount and the sizes of oxide particles were changed. EDX analysis combined with SEM and AFM clearly showed that rough surfaces were obtained. Having rough surfaces would be helpful for bonding to another material. However, in the micro-nano scale it is clear that the inhomogeneous mechanical and chemical properties were obtained, most probably resulting in inhomogeneous crack initiation.
\end{abstract}

DOI: 10.12693/APhysPolA.129.759

PACS/topics: 82.45.Cc

\section{Introduction}

Titanium oxide films are among the most popular metal oxides used in a very wide application area from aerospace industry [1] to biomedical engineering [2], due to their superior properties. Surface morphology plays an important role in most of the applications e.g. in biomedical engineering, the roughness of the surface alters the biomechanical fixation and osseointegration [2]. In most of the biomedical applications, such as the dental and orthopedic implants, the mechanical properties of the titanium oxides are also as essential, as the surface morphology, as they function under large forces [3]. Thus, it becomes important to prepare a titanium oxide surface that has both good mechanical properties and a good surface morphology.

In this study, it is aimed to investigate the effect of surface roughness on the mechanical properties of titanium oxides fabricated by anodization technique. Nanoindentation technique was used to investigate the mechanical properties, such as hardness and reduced modulus, of the thin titanium oxide coatings on the pure titanium, since it gives the information by measuring the indentation depths at the nano-scale level.

\section{Materials and methods}

Pure titanium (99.5\%) obtained from a vendor was used as the base material. It was ground with 1200 and then 2400 grit $\mathrm{SiC}$ paper. After grinding, samples were

*corresponding author; e-mail: nsarica@gmail.com polished with $3 \mu \mathrm{m}$ and $1 \mu \mathrm{m}$ diamond grit. Before the anodization procedure, samples were cleaned in acetone, isoprophyl and methanol respectively.

Sulphuric acid solution was used to prepare four different titanium oxide surfaces, having different surface nano-roughness and different morphologies, by applying $10 \mathrm{~V}$ and $50 \mathrm{~V}$ for $10 \mathrm{~min}$ and $45 \mathrm{~min}$, in order to investigate the effect of different morphologies on the mechanical properties of these oxides [4].

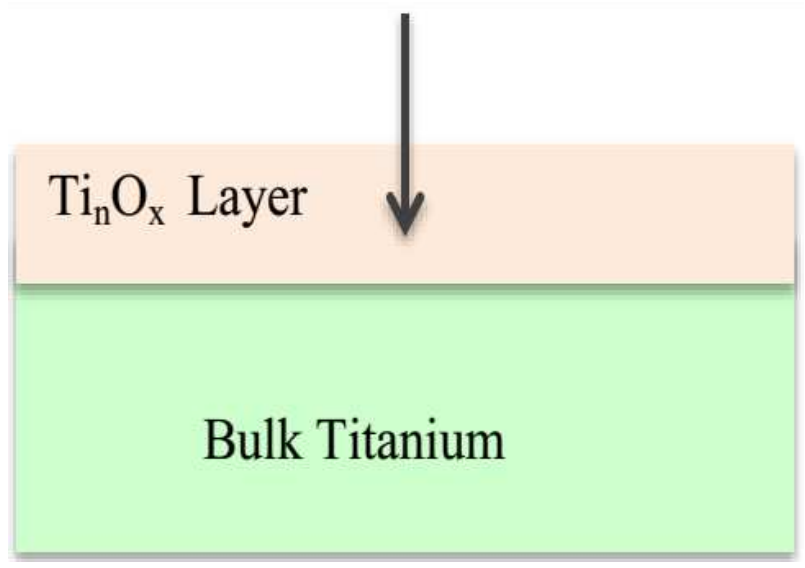

Fig. 1. Schematic diagram of nanoindenter, showing the maximum penetration depth of $40 \mathrm{~nm}$.

SEM studies were performed by using Jeol. Nanoindentation system, Micro Materials Ltd, was used to perform nanoindentation tests. In all tests the loading rate was of $0.15 \mathrm{mN} / \mathrm{sec}$ and the maximum penetration depth was chosen to be $40 \mathrm{~nm}$ [4]. Thus it was ensured 
that the penetration depth remains in the oxide layer as shown in Fig. 1. Time between loading and unloading was $60 \mathrm{~s}$. A number of 30 indentations were performed on each sample by using Berkovich indenter, having a face angle of $65.3^{\circ}$.

\section{Results and discussions}

Titanium oxide coatings on the surfaces are very thin so that conventional XRD machine cannot detect the titanium oxide layer on the surface. However, EDX analyses revealed the presence of oxide coating on the surface [4]. Results of the SEM of the titanium oxide coated samples are shown in Fig. 2. It is observed that as the anodization voltage was increased from $10 \mathrm{~V}$ (Fig. 2a, Fig. 2b) to $50 \mathrm{~V}$ for $10 \mathrm{~min}$ and $45 \mathrm{~min}$, the sizes of particles (grain size) on the surfaces have also increased and rougher surfaces were obtained, as seen in Fig. 2c and Fig. 2d, respectively. AFM studies also confirm this data [4].
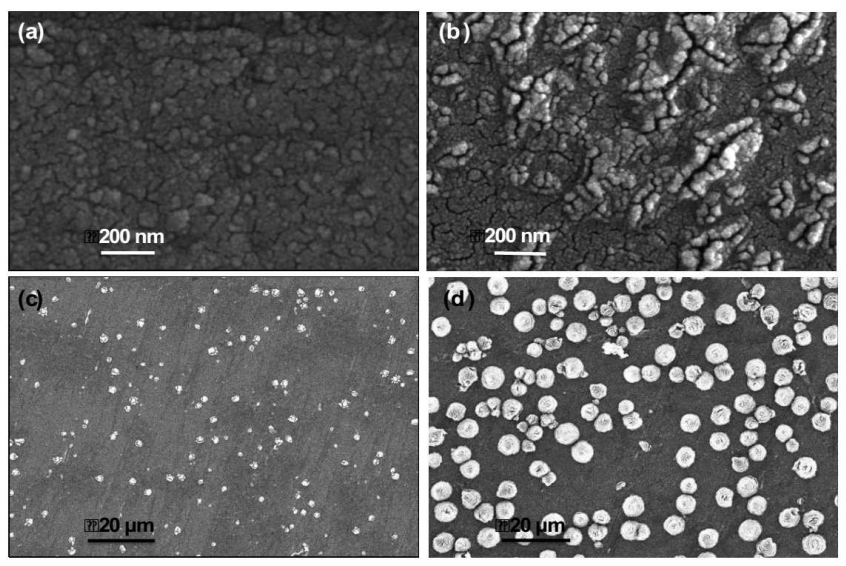

Fig. 2. SEM images of samples fabricated by applying (a) $10 \mathrm{~V}$ for $10 \mathrm{~min}$, at $800000 \times$, (b) $10 \mathrm{~V}$ for $45 \mathrm{~min}$, at $80000 \times$, (c) $50 \mathrm{~V}$ for $10 \mathrm{~min}$ at $1000 \times$, (d) $50 \mathrm{~V}$ for $45 \mathrm{~min}$ at $1000 \times$.

Hardness variations results obtained for the samples via nanoindentation tests are seen in Fig. 3. It is seen that hardness values of samples show deviations, as seen in Fig. 3a, Fig. 3b, Fig. 3c and Fig. 3d, which may result from the inhomogeneity of the oxide surface in terms of chemistry and surface morphology. Roughness is due to growth kinetics of new titanium oxides, new solid solutions consisting of $\mathrm{Ti}$ and $\mathrm{O}$ with different oxygen ratios. There might be even a very little amount of pure titanium at the conditions of $10 \mathrm{~V}$ at $10 \mathrm{~min}$ (Fig. 2a) compared to the other oxidation conditions (Fig. 2b, Fig. 2c, Fig. 2d), where there is nor pure titanium on the surface. Resistance to indentation shows difference between pure titanium and the other phases in the case of $10 \mathrm{~V}$ at $10 \mathrm{~min}$ (Fig. 3a) compared to the other conditions (Fig. 3b, Fig. 3c, Fig. 3d). That is reflected in a higher amount of deviation in terms of hardness and reduced modulus, as seen in Fig. 3a and Fig. 4a, respectively. Among all samples, the sample fabricated by applying $10 \mathrm{~V}$ for $10 \mathrm{~min}$ (Fig. 3a) has the highest hardness value than the other samples. Sample that has the largest particle size and roughness has in turn the lowest hardness value (Fig. 3d). According to the HallPatch equation, it is reported that when the average grain size of the material decreases, the hardness of the material increases [5], which is in accordance with our data. Hardness values of samples fabricated by applying $10 \mathrm{~V}$ for $45 \mathrm{~min}$ (Fig. 3b) and $50 \mathrm{~V}$ for $10 \mathrm{~min}$ are situated in the middle of the obtained range of values.
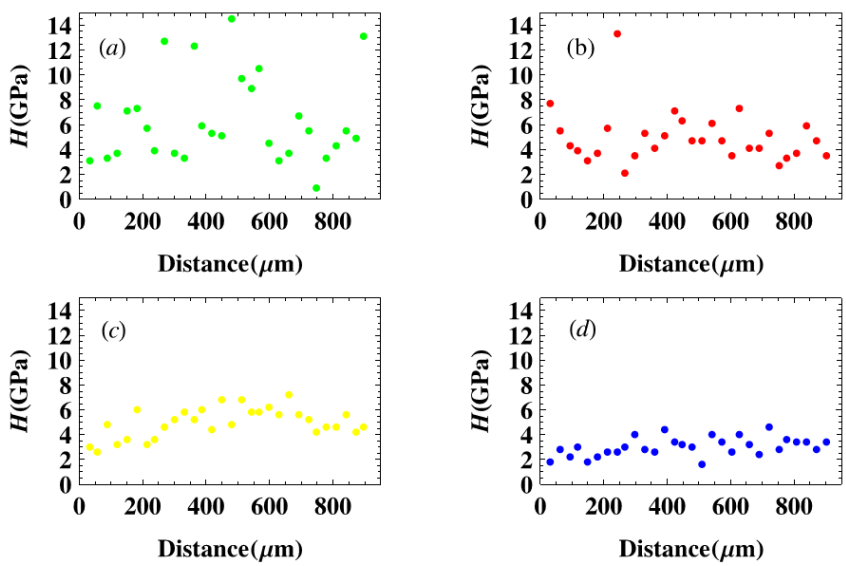

Fig. 3. Hardness variations of samples fabricated by applying (a) $10 \mathrm{~V}$ for $10 \mathrm{~min}$, (b) $10 \mathrm{~V}$ for $45 \mathrm{~min}$, (c) $50 \mathrm{~V}$ for $10 \mathrm{~min},(\mathrm{~d}) 50 \mathrm{~V}$ for $45 \mathrm{~min}$.

Reduced modulus parameters of the samples obtained via nanoindentation are seen in Fig. 4. As with the hardness parameters, the reduced modulus of samples also shows variations due to inhomogeneity of oxide particles distributed over the sample, as seen in Fig. 4a, Fig. 4b, Fig. 4c and Fig. 4d.
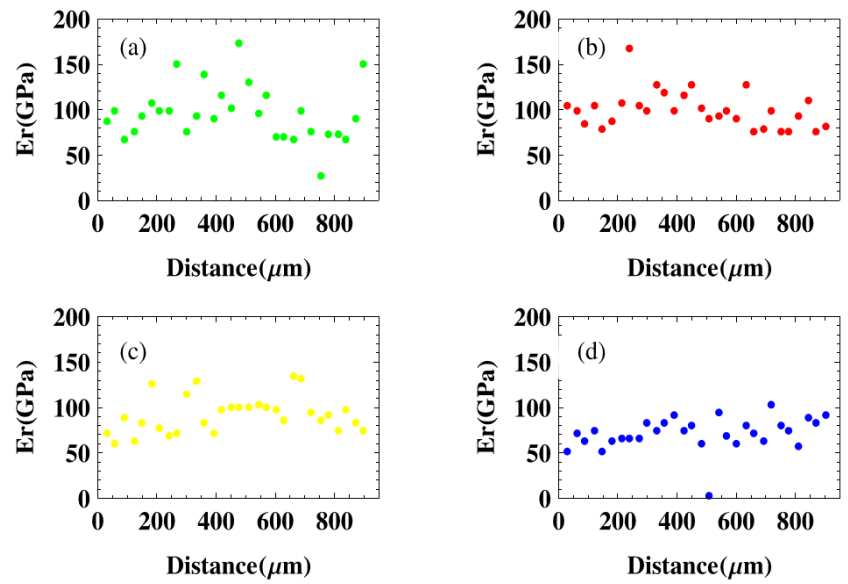

Fig. 4. Reduced modulus analyses of samples fabricated by applying (a) $10 \mathrm{~V}$ for $10 \mathrm{~min}$, (b) $10 \mathrm{~V}$ for $45 \mathrm{~min}$, (c) $50 \mathrm{~V}$ for $10 \mathrm{~min}$, (d) $50 \mathrm{~V}$ for $45 \mathrm{~min}$. 


\section{Conclusions}

In this study, the effects of grain sizes and roughness parameters on the hardness behavior of the samples were investigated. It was found, that surface roughness, which is helpful for the osseointegration, affects the mechanical properties, such as hardness and the reduced modulus. In all of the samples, hardness and reduced modulus parameters showed variations, which may result in inhomogeneous crack initiation. However, the nano-level roughness increases the total surface area, which would be helpful to have a better adhesive bonding with the other suitable materials.

\section{References}

[1] G. Lu, S.L. Bernasek, J. Schwartz, Surf. Sci. 458, $80(2000)$.
[2] H.S. Kim, Y. Yang, J.T. Koh, K.K. Lee, D.J. Lee, J. Biomed. Mater. Res. Part B: Appl. Biomater. 88B, 427 (2009)

[3] S.S. Samandari, C.C. Berndt, K.A. Gross, Acta Biomater. 7, 874 (2011).

[4] N. Sarıca, N. Nishikawa, C. Bindal, Z.Z. Öztürk, A.H. Üçışı, Altering of Nanoscale Properties of Oxide Layer on Titanium by Changing Anodization Parameters in 7th International Powder Metallurgy Conference and Exhibition, (Gazi University, Ankara, 24-28 June 2014).

[5] H. Yaghoubi, N. Taghavinia, E.K. Alamdari, A.A. Volinsky, ACS Appl. Mater. Inter. 2, 2629 (2010). 